\title{
DEVELOPING A LOCATION MODEL FOR FAST CHARGING INFRASTRUCTURE IN URBAN AREAS
}

\author{
A. SHIRMOHAMMADLI ${ }^{1} \&$ D. VALLÉE ${ }^{1}$ \\ ${ }^{1}$ Institute of Urban and Transport Planning, RWTH Aachen University, Germany.
}

\begin{abstract}
The potential of reducing greenhouse gases in transport sector attracted different groups to promote electric vehicles (EVs) as a component of sustainable mobility development. However, studies assert that the usage of EV is currently limited mainly to short-distance trips and the users are only those who have the opportunity of charging their car privately at home or workplaces. This research highlights the lack of public charging stations and tries to develop a demand-oriented location model for finding the optimal location of fast charging stations (FCSs) from a user's point of view. In urban areas the users can make use of activity time of their daily routine activities such as supermarket shopping for charging the battery of their EVs. Therefore, the proposed location model focuses on the interaction between people's travel behaviour and urban infrastructure. First, the potential of a facility for installation of FCS is determined by means of its different attributes such as number of attracted motorized individual trips, opening hours and parking lot availability, activity time of users in different facilities in relation to the charging time and synergy effect of closely allied facilities. In the second step, the study area is zoned and the calculated potential for facilities is transferred to the relevant zones, considering users' maximum detour acceptance, catchment area of facilities as well as spatial impact of existing charging stations. The input data, which rely mainly on open source and publically accessible data, are analysed and depicted as different georeferenced layers in the geographical information system (ArcGIS Software). The proposed location model aims to cover the growing demand for public FCS of current EV users as well as one step forward to increase the acceptance of electro mobility among potential users. Keywords: Electro mobility, fast charging station, location model, urban areas.
\end{abstract}

\section{INTRODUCTION AND LITERATURE REVIEW}

\subsection{Background of the problem}

Nowadays climate change is one of the most important and complex issues which gained a significant attention of different groups and societies. In this context there are plenty of efforts in national and international levels to improve the efficiency of energy consumption in different sectors such as industry, household and transport. The potential of optimizing the energy consumption in transport sector attracted many groups of stakeholders, which has resulted in clean and high efficient technologies in automotive industry such as hybrid, hydrogen and electric vehicles (EVs) in recent years. Electro mobility, as an important component of sustainable

This paper is part of the proceedings of the 22nd International Conference on Urban Transport and the Environment (Urban Transport 2016)

www.witconferences.com
} 
mobility development, cleans up the local air pollution, slashes global $\mathrm{CO}_{2}$ emission and, through its efficient energy consumption compared to conventional internal combustion engine vehicles, allows the growing renewable energies to play even more significant role in reducing the fossil fuel dependency. Despite the excessive ecological advantages of electro mobility, its acceptance among people was not so promising due to several issues. Besides high purchase price and limited range of EVs, one of the main reasons for low acceptance of EVs is lack of public charging facilities which limits EV users to only those who have the opportunity of charging their car privately at home or work places [1]. Capturing new groups of EV users requires a comprehensive development of publically accessible charging infrastructures which include a wide variety in terms of their technical properties. Whereas the conventional slow and normal AC charging processes take several hours to load the battery of an $\mathrm{EV}$, the fast charging technology supplies a high DC power which not only saves a large loss of power compared to AC charging, but it could also load the battery of EVs within 30 to 60 min (depending on the efficiency of charging stations and battery capacity) which provides a great flexibility for the users in the urban areas. Moreover, it gives the possibility of travelling long-distance intercity trips which could be an intermediate solution for the limited range of EVs before it is technically solved. However, high installation cost of FCSs and missing business models for suppliers are significant barriers to establish an extensive fast charging network. In this regard the determination of optimal location for fast charging infrastructure plays a key role to ensure their long-term profitability and operatability. This research aims to present an efficient and transparent location model for FCSs in urban areas. The basis of this model is the use case of FCSs to increase the flexibility of users with their daily routine activities as well as people's travel behaviour in urban areas. It is also a great pleasure to appreciate all those people who supported the authors during this work, especially Mr Pradeep Burla for his outstanding contribution. In accordance with the topic of the research, the next section gives a brief insight into the location models of FCSs which are implemented in practice.

\subsection{FCS location models in practice}

In recent years, plenty of research works and projects analysed the location problem of FCSs with different approaches and points of view Some researchers viewed this problem from the aspect of electricity supply grid, considering objectives such as reducing power losses or/ and reducing voltage deviation [2-4]. Some others investigated the economics and business cases of this technology, focusing on profitability objectives such as return of investment based on some assumptions and scenarios, e.g. development and penetration of EVs in the market, utilization level of charging stations and the price of electricity in the charging stations [5-7]. Some researchers explored the problem from the point of view of users' behaviour, which is the case in this article as well. This approach is generally divided into two categories considering major highways and urban areas. Concerning the limited range of EVs and the perceived range anxiety of users for long-distance trips, the provision of FCSs on the major highway has been the first priority of many researches and policies in recent years [8-10]. However, according to the research by Morrissey et al. [11] the provision of FCSs on highways satisfies mainly the demand of rural residents by their long-distance trips while a larger group of potential users in major cities are ignored or simply dismissed due to mainly short-distance regional trips in urban areas with the simplification that the length of urban trips won't exceed the range of EVs. This research indicates that over-focusing on covering the demand on highways may not be appropriate for all users, and demand in the major cities 
should be taken into account more seriously. In this regard, there are some researches which investigate the optimal location of FCSs in the urban areas. Baouche et al. [12] utilized the classical location models of p-dispersion and fixed charge location problems, and Zhu et al. [13] presented an extended version of this model by means of a genetic algorithm-based method in order to determine the location and size of charging stations, considering the construction costs and travellers' charging convenience. Another study [14] utilized p-median and maximal covering location model for determining the optimal location of FCSs in Beijin. The mentioned studies were based on classical location models and utilized OD matrix for locating the FCSs in urban areas; however, some other studies focus on charging and travel behaviour of users instead of mentioning typical location models which allow the modeller to implement different use-case scenarios based on the user studies or other user behavioural assumptions [15]. The presented location model in this article also explores the potential of locations for installation of FCSs from the point of view of users' behaviour and considers the urban structure and transport planning aspects.

The reminder of this article is organized as follows. The next section presents the algorithm and calculation method of the location model and relevant input parameters and criteria. The proposed model will be implemented by means of geographical information system (ArcGIS software) in the real case of city of Cologne/Germany and the results will be presented in Section 3. The last section is dedicated to discuss the plausibility of the results, ways to further development and other possible application of the proposed model.

\section{METHODOLOGY}

As mentioned earlier the use case of FCSs in urban areas is supposed to increase the flexibility of EV users with their daily routine activities, whereas the users can make use of activity time in different facilities in order to charge the battery of their EV. In other words, charging an EV by itself is not considered as a trip purpose but it is a sub-activity which will be done while the user is doing his/her main activity. In this regard, the key idea of the proposed location model in this article relies on the potential of different urban facilities to attract the motorized individual traffic (MIT). The activity time of users is an important criterion for determining the potential of a facility, and the better matching of activity time with charging time results in greater potential of the facility. The users' comfortability during the charging process will also be regarded in the model through the indicators of opening hours and parking place availability of a facility. The calculated number of MIT of each facility combined with activity time and comfortability of users results in the potential of a facility. Consequently the potential of facilities will be aggregated in the corresponding zones, considering different factors, e.g. influence area of urban facilities and effect of existing charging infrastructures. The workflow of the location model has been summarized in Fig. 1.

\subsection{Motorized individual traffic}

This criterion defines that the more attracted MIT to a facility, the greater is the potential of this facility for installation of FCS. The facilities that are the destination of trips with the purposes of 'work' and 'return to home' were dismissed here because the activity time was not matching with the fast charging time process. The activity time that plays an essential role in the potential of a facility will be discussed in Section 2.2 separately. The attracted number of MIT to a facility has been estimated by means of the following factors. 


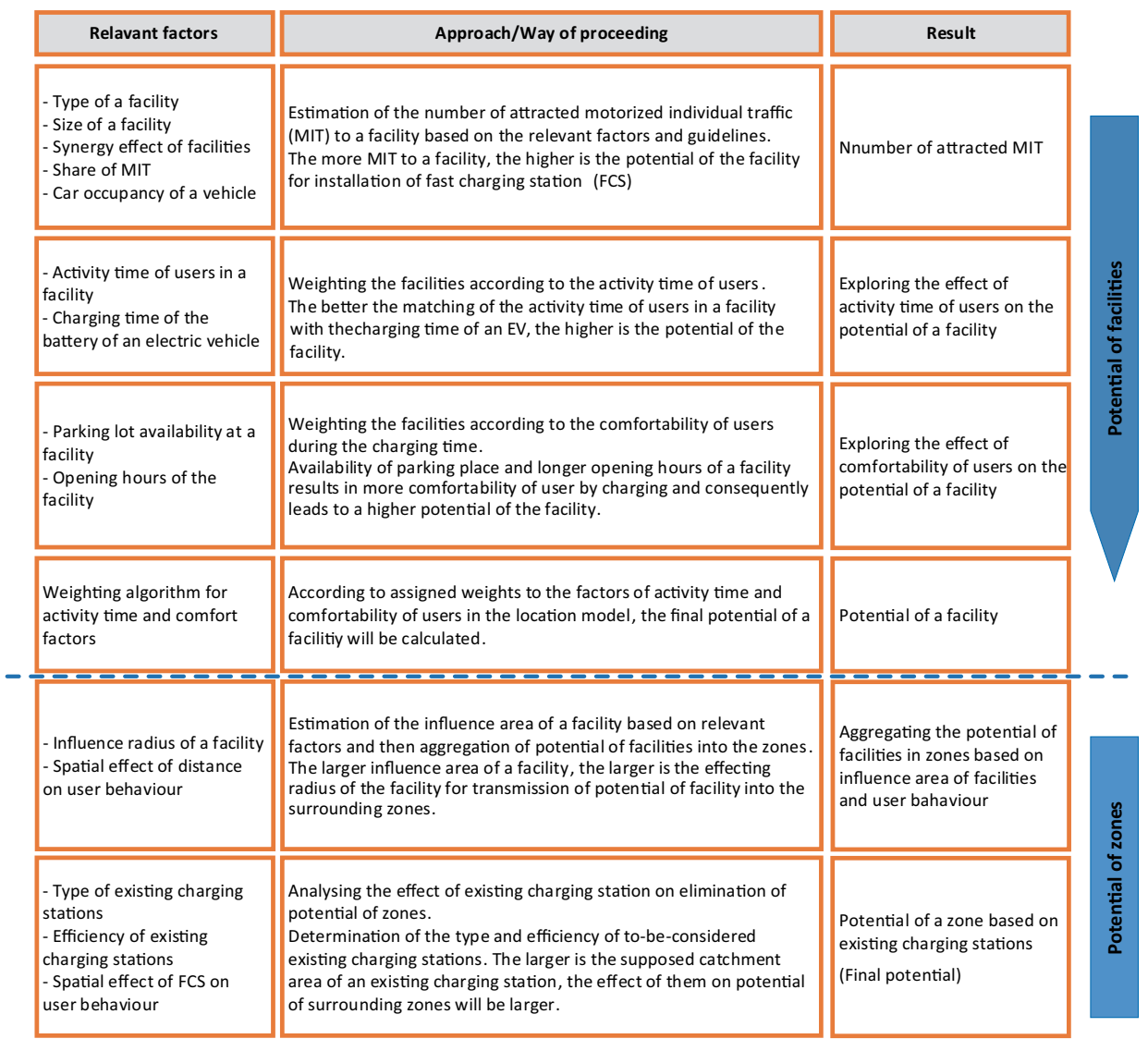

Figure 1: Criteria and steps of location model for installation of FCSs.

\subsubsection{Type and size of facility and synergy effect}

Here we are utilizing the guidelines introduced by Bosserhoff [16] and Vogt and Bosserhoff [17] in order to estimate the number of attracted people (customers, visitors) to a facility based on the type and size of the facility. For example a grocery store with up to $800 \mathrm{~m}^{2}$ sale floor attracts daily $1.00-1.20$ customers $/ \mathrm{m}^{2}$ or a cinema attracts $0.90-1.2$ visitors/seat. The variation between minimum and maximum values depends on the type of urban area where the facility is located. The facilities in cities with densely settled neighbourhoods attract higher number of customers/visitors while those located in sparsely populated areas outside the cities attract less. Moreover, the closely located facilities in a dense urban area could cause a synergy effect for attracting customers/visitors which could result in miscalculation of estimated number of attracted customers/visitors. Even if a customer visits several closely located facilities, the number of attracted people is still one but without attention to the synergy effect, it will be calculated multiple times mistakenly.

\subsubsection{Share of MIT trips and degree of car occupation}

This section calculates the number of attracted MIT out of the number of attracted customers/visitors by differentiating the travel model and the passenger occupancy of a vehicle. The share of MIT trips depends on trip purpose, which will be identified by the type of facility, 
and also strongly on the type of urban area. The share of MIT trips in the city centres is much lower than that in outside areas because of the dense public transport network, more biking and walking trips due to shorter trip distances, difficulties in finding a parking place, speed limitations, toll costs and so on. In addition, the occupancy rate of passenger vehicles should be regarded in order to calculate the number of MIT trips out of attracted people. To get an integrated result with previous section, we utilize as before the guidelines from Bosserhoff [16] and Vogt and Bosserhoff [17].

\subsection{Activity time}

As it has already been mentioned, the user could make use of daily activity time such as shopping or leisure in order to charge the battery of his/her EV. The better the matching of the activity time with charging time, the larger is the potential of the facility for FCSs. Therefore, the activity time of users should be evaluated in relation to the charging time of battery. The charging time depends on different technical features of battery, FCSs as well as state of charge of battery. It means that an empty battery gets charged faster at the beginning and as the battery fills up the charging process becomes slower. Simply speaking, charging process up to $80 \%$ of a $24 \mathrm{kWh}$ battery by means of a $50 \mathrm{~kW}$ FCS takes roughly $30 \mathrm{~min}$ and the remaining $20 \%$ of battery also takes the same time [18]. With this simplification, the following charging graph and rating sketch have been utilized for comparing and evaluating the activity time of users in different facilities (Fig. 2).

In this article the activity time less than 15 min has been considered as very short but is still useful in emergency cases; about 15 to $30 \mathrm{~min}$ is the period in which the user plugs out the charger while he/she still could have utilized the efficient and fast charging process. The best rating has been assigned to an activity time between 30 and 60 min because the user has had full advantage of the efficient charging process (up to $80 \%$ of battery) and then leaves the charging station when the charging process is getting slower. After 60 min the battery is already full; however, occupying the stations would add up to additional $60 \mathrm{~min}$. When the activity time exceeds 120 min then the FCS is not a proper investment because the charging demand could be satisfied by not-so-fast charging infrastructures, installation costs of which are much less than an FCS.

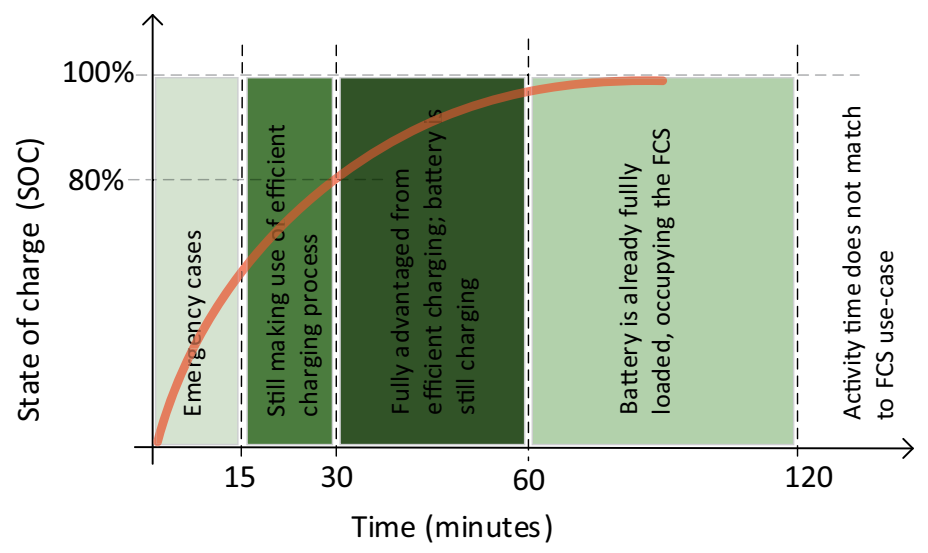

Figure 2: Simplified state of charge of battery and categorization of activity time (Source: author's illustration). 


\subsection{Comfort by charging}

This section explores the factors which indicate the comfort of users during the charging process, and the idea behind this criterion is that the more comfortable the charging is, the potential of the facility for installation of an FCS is greater. The following factors have been selected as the determining factors for comfort of users during the charging process.

\subsubsection{Parking lot availability}

This factor increases the comfortability of users of EVs because availability of a parking lot directly at a facility, where the EV could be parked and charged, will not only save the time spent on searching for a parking place but also the facility will be reachable without any walking detour. The walking detour is an important factor especially for shopping facilities, in which the purchased goods should be carried to the vehicle.

\subsubsection{Opening hours}

The longer opening hours of the facilities address the more comfortability for the user for utilizing the charging station. To simplify this factor, the opening hours of facilities are categorized into four classes: first one includes 5 days/week-open facilities such as banks or other administrative offices; second one includes 6 days/week-open facilities e.g. supermarkets and discounters; third class includes 7 days-working facilities but not round the clock e.g. restaurants; and finally the 24/7-open facilities such as gas stations.

\subsection{Weighting algorithm}

The number of attracted MIT is employed as base potential of each facility and the matching of activity time with charging time and the comfort of users during the charging process will be utilized as weighting criteria. For this purpose, the values of the criteria should be quantified in a unified way, in which value one assigns to the best situation of a criterion and the worst case corresponds to value zero. In so doing the following values will be assigned for each criterion:

Activity time:

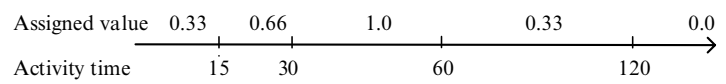

Parking place availability:

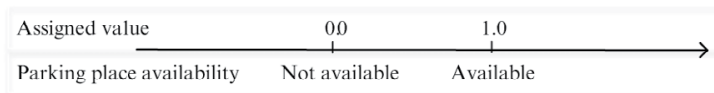

Opening hours:

\begin{tabular}{|c|c|c|c|c|}
\hline Assigned value & 0.0 & 0.33 & 0.66 & 1.0 \\
\hline Opening hours & Class 1 & Class 2 & Class 3 & Class 4 \\
\hline
\end{tabular}

After quantifying the criteria, the following scheme has to be utilized for weighting the potential of a facility (Fig. 3): 


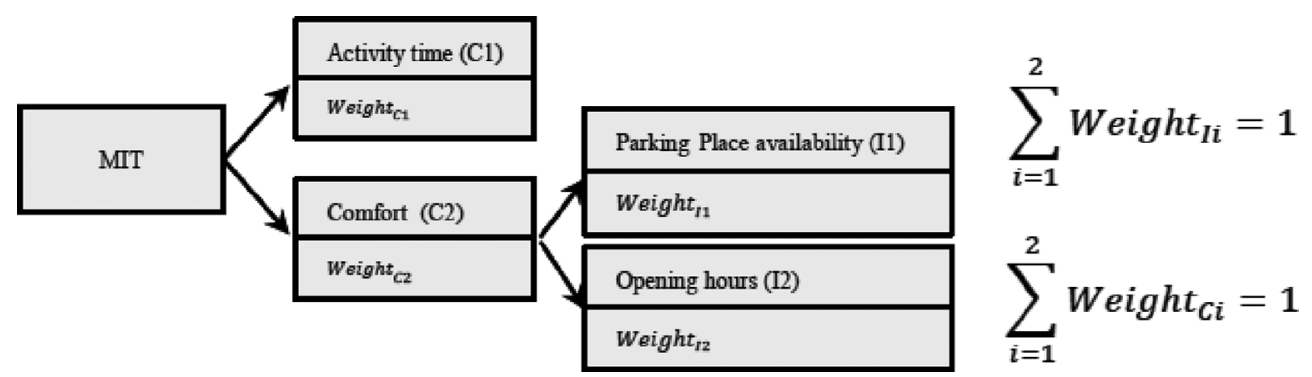

Figure 3: Weighting scheme for calculating the potential of a facility.

The potential of a facility $\left(\mathrm{PoF}_{i}\right)$, considering the weights of criteria ( Weight ${ }_{C 1}$ and Weight $_{C 2}$ ) and indicators ( Weight ${ }_{I 1}$ and Weight ${ }_{I 1}$ ), is calculated as below:

$$
\text { Potential of Facility } i=\operatorname{MIT}_{i} *\left[\left(C 1 * \text { Weight }_{c 1}\right)+\left(\text { Weight }_{c 2} \sum_{i=1}^{2} I i * \text { Weight }_{I i}\right)\right]
$$

\subsection{Aggregation of potential of facilities in zones}

By now the potential has been calculated for facilities which presents the potential in one single point, where a facility is located. This section deals with determination of the potential of an area instead of a point through transmission and aggregation of calculated potential of facilities into their surrounding areas. Important challenges for this purpose are firstly to define the area, under the influence of which the potential of a facility is, and then to specify the spatial properties of potential within the defined influence area, and both of them will be described based on the users' behaviour regarding the acceptance of distance between charging station and the to-be-considered facility.

The main assumption to define the influence area or maximum influence radius of a facility is that the user parks his/her EV at the charging station and then goes to the facility on foot; the maximum distance travelled on foot is considered as influence radius of the facility. However, the influence radius is not the same for all facilities and varies according to the type and size of the facility as well as carriage of goods. For example, it is supposed that the users accept longer distance to reach a leisure facility, such as restaurant or cinema, than to a shopping facility that they visit almost daily, such as supermarkets from where the purchased goods should be carried; therefore the influence radius of restaurant and cinema is supposed to be larger than that of a supermarket. In so doing, the facilities have been classified into two categories in terms of maximum influence radius. Orienting to the average speed of pedestrians, the influence radii were set to be 250 and $500 \mathrm{~m}$ for these categories, which are equal to ca. 4 and 8 min walking time [19]. After the definition of the maximum influence radius of facilities, the second step clarifies the properties of potential within the influenced area. The main supposition is that the closer is an area to a facility, the influence of the facility is greater, and when getting farther from the facility, the influence weakens. Regarding the fact that utilizing distance as a continuous parameter in location model would result in very huge calculation complexity, the area under study is divided into square-shaped zones with sides of 

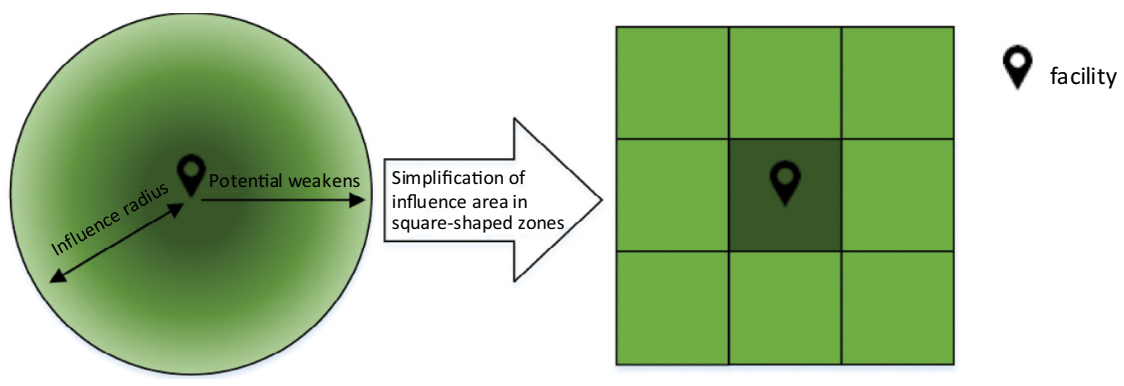

Figure 4: Influence radius of a facility and decreasing the potential of farther areas; simplification and zoning the area under study in square-shaped zones.

$250 \mathrm{~m}$ length to simplify the calculations and implement the considered maximum influence radius conveniently (Fig. 4).

The calculated potential of each facility will be assigned completely to the zone, where the facility is located, and then a fraction $(\alpha ; \alpha<1)$ of the potential of the facilities with greater influence radius $(500 \mathrm{~m})$ will be assigned to the neighbouring zones, which are located within 250-500 $\mathrm{m}$ distance (from the facility to cetroid of zones).

\subsection{Existing charging stations}

This section considers the effect of existing charging stations on the potential of a zone. However, since the efficiency of charging infrastructures plays a most notable role in determining the charging time, and also due to incompatibility of different plug-in types of FCSs, the efficiency and plug-in type of to-be-located FCSs should be specified and fed as input parameters in location model. Hereafter, the spatial effects of specified existing charging stations on the potential of relevant zones (the same zone and neighbouring zones) should be investigated. This effect is implemented in the location model by considering the same assumptions of behaviour of EV users regarding the acceptance of on-foot detour. The potential of a zone, in which an FCS already exists, will be reset to zero because it is assumed that the whole demand for fast charging will be satisfied using this station. The reduction of potential of neighbouring zones within 250-500 m depends on the type of facilities in these zones. A part of the potential in neighbouring zones that are originated from facilities with influence radius of $500 \mathrm{~m}$ could be satisfied using the existing station. For this purpose the same factor of $\alpha(\alpha<1)$ for reduction of potential in neighbouring zones has been utilized.

\section{RESULTS}

\subsection{Study area}

In order to implement the introduced methodology in real case, the city of Cologne with over $400 \mathrm{~km}^{2}$ area and one million population in the west of Germany has been selected; it is large enough to implement the presented location model. The required input data for location model in this area have been collected from different sources and edited in the form of georeferenced shapefile layers so that they could be combined and spatially analysed in ArcGIS software (Fig. 5). 


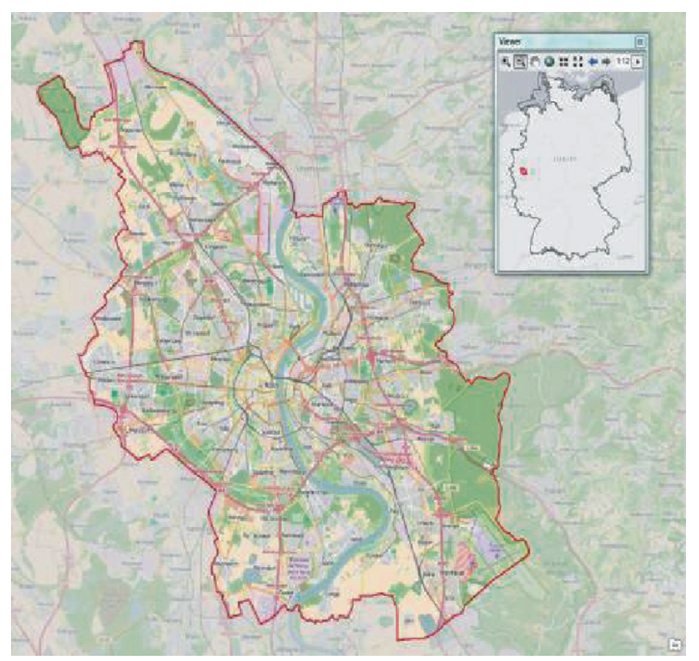

Figure 5: Study area of city of Cologne/Germany (Source: Open Street Map).

\subsection{Potential of a facility}

An important input parameter for estimating the attracted MIT to urban facilities is the size of a facility. The size of many well-known chain facilities such as ALDI and Lidl discount supermarkets was investigated and fed in the model; however, gathering these data for all individual facilities is a time-consuming process. To deal with this problem, the remaining facilities of the same type were aggregated and an average size for each category was assigned. The attracted MIT for each facility was estimated as follows:

$$
\mathrm{MIT}=\frac{(\text { Size }) *(\text { Customer } / \text { unit }) *(\text { MIT Share })}{(\text { Passenger per car })} *(1-\text { Synergy effect })
$$

According to the type of urban area, this formulation employs a maximum, minimum or an average value for the number of attracted customers/unit and MIT share. The calculation of attracted MIT for an exemplary set of facilities has been presented in Table 1.

Table 1: Estimation of attracted MIT to a facility (selection facilities).

\begin{tabular}{|c|c|c|c|c|c|c|c|c|}
\hline \multirow{2}{*}{$\begin{array}{l}\text { Name/cat- } \\
\text { egory }\end{array}$} & \multirow[t]{2}{*}{ Size } & \multicolumn{2}{|c|}{ Customer/unit } & \multicolumn{2}{|c|}{ MIT share } & \multirow{2}{*}{$\begin{array}{c}\text { Passenger } \\
\text { per car }\end{array}$} & \multirow[t]{2}{*}{ Urban area } & \multirow{2}{*}{$\begin{array}{c}\text { Attracted } \\
\text { MIT }\end{array}$} \\
\hline & & Min & Max & Min & Max & & & \\
\hline ALDI & 800 & 2.00 & 2.50 & 0.40 & 0.60 & 1.3 & Suburban & 692 \\
\hline REWE & 1,420 & 1.00 & 1.20 & 0.40 & 0.60 & 1.3 & Centre & 524 \\
\hline IKEA & 25,000 & 0.35 & 0.50 & 1.00 & 1.00 & 1.9 & Outside & 4,605 \\
\hline OBI & 7,700 & 0.15 & 0.45 & 0.65 & 1.00 & 1.35 & Suburban & 1,412 \\
\hline FITNESS & 2,000 & 0.15 & 0.30 & 0.90 & 1.00 & 1.1 & Centre & 491 \\
\hline
\end{tabular}

It is assumed that the above introduced exemplary facilities cause no synergy effect. After calculating the number of attracted MIT as base potential, the effect of activity time and comfort on the base potential will be explored. However, determination of weights of these 
factors requires an additional user behaviour analysis which is not the focus in this research; therefore weights have been set equally in this research $\left(\right.$ Weight $_{C \mathrm{i}}=0.5$ and Weight ${ }_{I i}=0.5$ ) (Table 2).

Table 2: Calculation of potential of each facility considering the equal weights of factors (selection facilities).

\begin{tabular}{lccccr}
\hline \multirow{2}{*}{$\begin{array}{l}\text { Name/Cat- } \\
\text { egory }\end{array}$} & $\begin{array}{c}\text { Attracted } \\
\text { MIT }\end{array}$ & Activity time & \multicolumn{2}{c}{ Comfort } & \multirow{2}{*}{$\begin{array}{c}\text { Potential of } \\
\text { facility }\end{array}$} \\
\cline { 4 - 5 } & & & Parking place & Opening hours & \\
\hline ALDI & 692 & 35 & Available & Class 2 & 576 \\
REWE & 524 & 35 & Not available & Class 2 & 305 \\
IKEA & 4,605 & 90 & Available & Class 2 & 2,291 \\
OBI & 1,412 & 45 & Available & Class 2 & 1,175 \\
FITNESS & 491 & 150 & Not available & Class 3 & 81 \\
\hline
\end{tabular}

\subsection{Potential of zone}

In this section the calculated potential of facilities will be aggregated to the square-shaped zones with regard to their influence area and spatial properties of potential within the defined influence area (value of parameter $\alpha$ ). The potential of facilities with limited influence radius is assigned only to the zone, in which the facility is located, while the potential of facilities with longer influence radius will also affect the direct neighbouring zones with the factor $\alpha$. Here it is assumed that $\alpha=0.5$; however, the determination of this value should be done via user behaviour analysis based on the acceptance of on-foot distance for different facilities.

\subsection{Effect of existing FCSs}

Due to different and partly incompatible technical properties of FCSs, the efficiency and type of plug-in system of to-be-considered FCSs should be determined and fed as input parameters in the location model. Here the efficiency of charging infrastructure set to $\geq 50 \mathrm{~kW}$ and plug-in type of combined charging system were chosen, which are introduced by German engineers to charge the battery of EVs of relevant car-maker companies.

After considering the effect of existing charging stations, the final potential of each zone is calculated, the value of which ranged from zero to 61,000. In order to illustrate the results, the values of potential have been categorized into four levels using 'Jenks natural breaks classification method' of ArcGIS software. The transparent zones in the depicted final results of Fig. 6 correspond to no or very low potential zones which are mainly located in non-residential areas (as expected), and the different green-tone colours correspond to higher potential zones in more densely settled urban areas. The utilized method to illustrate the potentials in this research is not the only unique way to present the results and it could be performed using different classification methods and/or a number of different potential categories. It should also be noted that although the categorization and illustration of potentials give a good overview of potentials in the areas under study, the final decision about optimal area should be taken based on the value of calculated potential. 


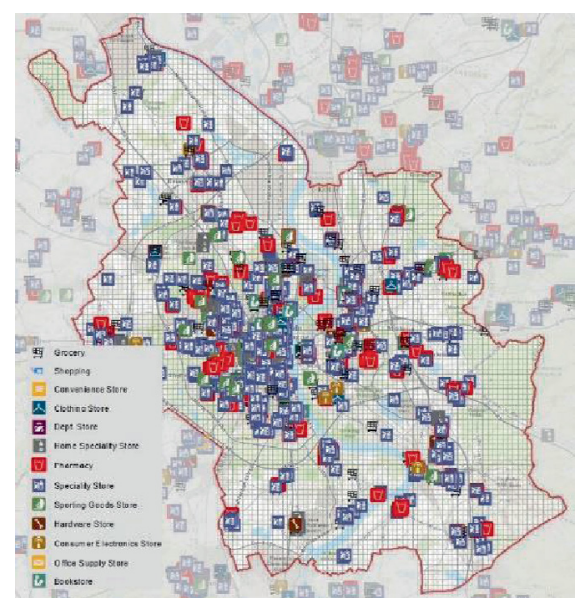

(a)

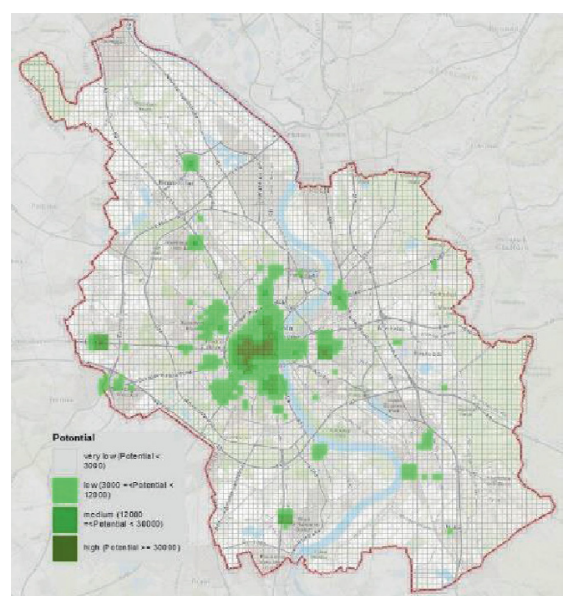

(b)

Figure 6: Selected facilities (shopping facilities) and zoning of cases under study (left) and final results of potential calculation of zones (right) (Source: www.maps. here.com).

\section{CONCLUSION}

The proposed location model tries to satisfy the growing demand for public FCSs of current EV users in the urban areas and make the electro mobility among potential users more attractive. Based on the use case of increasing flexibility of EV users with their daily routine activities, analysing the interaction between people's travel behaviour and urban infrastructure was the pillar of the presented location model. The location model delivers reasonable results in the area under study with no/very low potential in unsettled areas and higher potential in more dense areas. However, the results strongly depend on users' behaviour such as activity time, preference of comfortability through parking place availability and opening hours of facilities as well as charging behaviour of users in terms of maximum detour acceptance. The utilized values and weights for these parameters were based on limited literatures and researchers' assumptions; however, their proper values require an extensive user behaviour study. Moreover, other influencing factors, e.g. social security of different regions, installation costs, electricity grid supply, etc., could be followed in the steps for further developing the location model. The presented location model in this research is developed in a way that is easily adaptable for location problem of other refuelling infrastructures such as hydrogen or compressed natural gas stations.

\section{REFERENCES}

[1] Frenzel, I., Jarass, J., Trommer, S. \& Lenz, B., Erstnutzer von Elektrofahrzeugen in Deutschland. Nutzerprofile, Anschaffung, Fahrzeugnutzung, 2015.

[2] Wang, G., Xu, Z., Wen, F. \& Wong, K.P., Traffic-constrained multiobjective planning of electric-vehicle charging stations. IEEE Transactions on Power Delivery, 28(4), pp. 2363-2372, 2013. DOI: 10.1109/TPWRD.2013.2269142.

[3] Mohsenzadeh, A., Pang, C., Pazouki, S. \& Haghifam, M., Optimal siting and sizing of electric vehicle public charging stations considering smart distribution network reliability. In North American Power Symposium (NAPS), 2015 (pp. 1-6). IEEE. 2015. 
[4] Bayram, I. S., Michailidis, G., Devetsikiotis, M. \& Granelli, F., Electric power allocation in a network of fast charging stations. IEEE Journal on Selected Areas in Communications, 31(7), pp. 1235-1246, 2013. DOI: 10.1109/JSAC.2013.130707.

[5] Wirges, J., Linder, S. \& Kessler, A., Modelling the development of a regional charging infrastructure for electric vehicles in time and space. European Journal of Transport and Infrastructure Research, 12(12), 391-416, 2012.

[6] Schroeder, A. \& Traber, T., The economics of fast charging infrastructure for electric vehicles. Energy Policy, 43, pp. 136-144, 2012. DOI: 10.1016/j.enpol.2011.12.041.

[7] Zhu, Z. H., Gao, Z. Y., Zheng, J. F. \& Du, H. M., Charging station location problem of plug-in electric vehicles. Journal of Transport Geography, 52, pp. 11-22, 2016. DOI: 10.1016/j.jtrangeo.2016.02.002.

[8] Sathaye, N. \& Kelley, S., An approach for the optimal planning of electric vehicle infrastructure for highway corridors. Transportation Research Part E: Logistics and Transportation Review, 59, pp. 15-33, 2013. DOI: 10.1016/j.tre.2013.08.003.

[9] Zhang, L., Shaffer, B., Brown, T. \& Samuelsen, G.S., The optimization of DC fast charging deployment in California. Applied Energy, 157, pp. 111-122, 2015. DOI: 10.1016/j.apenergy.2015.07.057.

[10] Li, S., Huang, Y. \& Mason, S.J., A multi-period optimization model for the deployment of public electric vehicle charging stations on network. Transportation Research Part C: Emerging Technologies, 65, pp. 128-143, 2016. DOI: 10.1016/j.trc.2016.01.008.

[11] Morrissey, P, Weldon, P. \& O’Mahony, M., Informing the Strategic Rollout of Fast Electric Vehicle Charging Networks with User Charging Behaviour Data Analysis, Proceedings of the 95th Annual Meeting of the Transportation Research Board, National Academy of Sciences, Washington D.C. 2016.

[12] Baouche, F., Billot, R., Trigui, R. \& Faouzi, E., Efficient allocation of electric vehicles charging stations: optimization model and application to a dense urban network. Intelligent Transportation Systems Magazine, IEEE, 6(3), pp. 33-43, 2014. DOI: 10.1109/ MITS.2014.2324023.

[13] Zhu, Z.H., Gao, Z.Y., Zheng, J.F. \& Du, H.M., Charging station location problem of plug-in electric vehicles. Journal of Transport Geography, 52, pp. 11-22, 2016. DOI: 10.1016/j.jtrangeo.2016.02.002.

[14] He, S.Y., Kuo, Y.H. \& Wu, D., Incorporating institutional and spatial factors in the selection of the optimal locations of public electric vehicle charging facilities: A case study of Beijing, China. Transportation Research Part C: Emerging Technologies, 67, pp. 131-148, 2016.

[15] Giménez-Gaydou, D. A., Ribeiro, A. S., Gutiérrez, J., \& Antunes, A. P. (2016). Optimal location of battery electric vehicle charging stations in urban areas: A new approach. International Journal of Sustainable Transportation, 10(5), 393-405.

[16] Bosserhoff: Integration von Verkehrsplanung und räumliche Planung- Teil 2: Grundsätze und Umsetzung, Heft 42 der Schriftenreihe der Hessischen Straßen - und Verkehrsverwaltung, Wiesbaden 2000.

[17] Vogt, W. \& Bosserhoff, D., Hinweise zur Schätzung des Verkehrsaufkommens von Gebietstypen (Vol. 147), FGSV Verlag, 2006

[18] Hayes, J.G. \& Davis, K., Simplified electric vehicle powertrain model for range and energy consumption based on EPA coast-down parameters and test validation by Argonne National Lab data on the Nissan Leaf. In Transportation Electrification Conference and Expo (ITEC), 2014 IEEE (pp. 1-6). IEEE. 2014.

[19] Verband Deutscher Verkehrsunternehmen, Verkehrserschließung und Verkehrsangebot im ÖPNV, VDV Schriften, Heft 4, Köln 6/2001. 